\title{
Morphometric Overview on the Vascularization in the Egyptian Domestic Cat (Felis catus) Hind Paw
}

\author{
Hamdy Rezk, Nora Shaker*
}

*Department of Anatomy, Faculty of veterinary medicine, Cairo University

\section{Abstract}

The present study was conducted on 16 fresh cats' hind paws to investigate the anatomical description of the arterial blood supply at the level below the tarsus, which considered as the potential site for intra- operation hemorrhage and thrombus formation. Six cat hind paws with intravascular latex injection, four limbs for surgical approach and three cats used in Duplex ultrasonography technique as a tool for estimating the diameter of the arteries of hind paw of potentially clinical relevant. This work reported that, the hind paw of the cat was supplied by branches from the saphenous $A$. and the cranial tibial $A$. Both dorsal and planter aspects of the paw was supplied by superficial and deep sets of arteries; the superficial set consists of the common digital arteries II, III and IV While, the deep set was formed of the metatarsal arteries II, III and IV.

Keywords: Cat, arteries, duplex, ultrasonography, hind paw.

\section{Introduction}

The vascular anatomy of the digits and tendons of hind paws of the cat (as experimental model) is similar to the feet of the human (Jones, et. al.,2000 and Meredith, 2009). The acute changes in peripheral arterial flow patterns of sympathetically blocked lower limbs in anesthetized children, surgical procedure common performed in dog and cat to remove a diseased or injured limb (Limb amputation), also, the arterial puncture and catheterization is among the most important techniques required for monitoring the critically ill small animal patient. Diagnosing and examining conditions that affect the blood vessels of the distal segment of the artery such as the dorsal pedal arterial thrombosis which its complication lead to vascular necrosis of the metatarsal and pedal soft tissue is needed and became important.

This study aimed to provide detailed information on the blood supply of the hind paw of the cat which may prove clinically useful in noninva- 
sively predicting patency of these arteries (Caster et.al., 1992) as well as, helping in treating the previously mentioned problems.

\section{Material and methods}

This work was carried out on 16 hind paws (8 right and 8 left) were collected from eight fresh cat cadavers obtained from the Department of Anatomy, Faculty of Veterinary Medicine, Cairo University. Three cats were injected through the abdominal aorta using red latex vascular injection technique and were fixed in $10 \%$ formalin solution for 48-72hrs before dissection. The hind paw was dissected and the main arteries and their branches were studied. Additional dissection was performed on four hind paws to devise the medical surgical approach to the saphenous artery and cranial tibial artery at level of tarsus.

The anatomical structures were captured using a digital camera with 12-pixel resolution.

Three cats were used as a model for establishment of normal duplex ultrasonographic images to describe the vasculature in situ. Cats were prepared by withholding food for 24hours (fasting) before ultrasonograhic examination as previously described by Barr and Gaschen (2011).
The duplex ultrasonography was performed on the cats positioned on the lateral recumbence using a manual restraint on standard examination table. It were sedated by using xylazine $\mathrm{I} / \mathrm{M}$ as sedative tranquilizer at a dose of $(1.1 \mathrm{mg} / \mathrm{kg})$ and ketamine $10 \mathrm{mg} / \mathrm{kg} \mathrm{I/M}$ before this application as described by Bednarski (1996). The skin of the hind paw of cat was clipped and shaved.

The high-frequency, real time ultrasound system using probe (convex, cylindrical end viewing) with frequency 7.5 $\mathrm{MHZ}$ and coupling gel were used for ultrasonographic examinations with rotating the probe on the hind paw region medially and laterally on each aspect of it.

The nomenclature used was that recommended by the Nomina Anatomica Veterinaria (N.A.V.) (2005).

\section{Results}

The present study revealed that, the arterial blood supply of the cat hind paw was formed by smaller superficial and larger deep sets of branches. These sets were mainly formed by the saphenous and the cranial tibial arteries for both dorsal and planter aspects of the hind paw region.

In the cat hind paw, the 2nd, 3rd and 4th digits were considerably longer than the 5th digit. The plantar surface of the paw was related to 
the base of the 2nd, 3rd and 4th digits with two small fleshy volar pads. On removal of the plantar skin and superficial fascia the superficial digital flexor tendons was exposed. It originates from the calcaneal tuberosity and continues at the plantar region, superficial and lateral to the deep digital flexor tendon. Firstly it appears as single tendon then divided into four separate tendons, which eventually terminate in the 2nd, 3rd, 4th and 5th digit.

\section{Vascular anatomy}

The main two branches that supplied the dorsal surface of the hind paw were observed after dissection, the cranial branch of the saphenous artery (Fig.1/1) as well as the superficial branch of the cranial tibial artery (Fig 1/2).

\section{A. saphena}

The saphenous artery arose from the caudal aspect of the femoral artery at middle of the thigh, descends superficially to proximal part of the leg at distal extremity of tibia and terminated as two branches: a small cranial and large caudal branch.

\section{Ramus cranialis}

The cranial branch of the saphenous artery (Fig 1/1) passes obliquely disto-cranially, crosses the medial surface of tibia to the flexor surface of the hock joint, turning around the medial border of the cranial tibial muscle and continues distally in the superficial fascia covering this muscle. Opposite to the tarsal joint, the cranial branch detached the $2^{\text {nd }}$ dorsal common digital artery and a common trunk for the $3^{\text {rd }}$ and $4^{\text {th }}$ dorsal common digital arteries.

\section{Aa. digitales dorsales communes II, III, IV}

The dorsal common digital arteries II, III, IV (Fig 1 / 3, 4, 5 respectively) represented the superficial set of the arteries supplying the dorsal aspect of the hind paw, they derived from the anastomoses of the cranial branch of the saphenous artery and the superficial branch of cranial tibial artery. They situated subcutaneously over the tendon of the long digital extensor. These arteries descended in the intervals between the metatarsal bones where it anastomosed with the corresponding planter common digital artery through the interdigital artery (A. interdigitalis) (Fig 1/6). The $2^{\text {nd }}$ dorsal common digital artery detached the $2^{\text {nd }}$ lateral dorsal digital artery (Fig 1/7) at the level of the tarsal bones, while the $5^{\text {th }}$ lateral dorsal digital artery (Fig 1/8) originated from the common trunk of the $3^{\text {rd }}$ and $4^{\text {th }}$ dorsal common digital arteries about $1 \mathrm{~cm}$ below this level. 
The dorsal common digital arteries bifurcated just before the level of the metatarsophalangeal joint to give off the medial and lateral dorsal proper digital arteries II,III, IV (Aa. digitales dorsales propriae axiales et Aa. digitales dorsales propriae abaxiales II, III, IV) (Fig 1/9, 10).

\section{A. tibialis cranialis}

The cranial tibial artery descended on the cranial surface of the tibia and continued at the level of the tarsal joint as the dorsal pedal artery (A.dorsalis pedis) (Fig 2/11).

\section{A. tarsea medialis et A. tarsea lateralis}

The medial and lateral tarsal arteries (Fig 2/12, 13 respectively) arose from the dorsal pedal artery at the level of the tarsal joint, ran deeply to both sides of the tarsus and end in the collateral ligaments. The medial one arose proximal to lateral artery.

\section{A. arcuata}

The arcuate artery (Fig 2/14) is a small vessel which leaves the lateral side of the dorsal pedal artery at the proximal end of the metatarsus and run transversely till disappear in the ligament tissue.

\section{Aa. metatarseae dorsales}

There were three dorsal metatarsal arteries II, III, IV (Fig 2/15, 16, 17 respectively) represented the deep set of the arteries supplying the dorsal aspect of the hind paw. The $2^{\text {nd }}$ dorsal metatarsal artery was derived from the dorsal pedal artery. The third and fourth dorsal metatarsal arteries originated from the arcuate artery by a common stem. They descended in the inter-metatarsal spaces.

\section{Ramus perforans proximalis II}

The proximal perforating artery II (Fig 2/18) passed from the dorsal to the plantar surfaces of hind paw by passing in the space between proximal end of the second and third metatarsal bones and joined with the deep planter arch.

Two branches supplied the plantar surface of the hind paw were observed after dissection, the caudal branch of the saphenous artery and the proximal perforating branch of the cranial tibial artery.

\section{Ramus caudalis}

The large caudal branch of the saphenous artery (Fig $3 / 19$ ) was the direct continuation of the saphenous A. It lied medial to the tarsus, related to the flexor of digits and gave several tarsal branches (rami tarsici) to the skin and fascia of the medial surface of the tarsus.
A. plantaris medialis et A. planta- ris lateralis 
The medial and lateral planter arteries (Fig $3 / 20,21$ respectively) arose from the caudal branch of the saphenous artery distal and medial to the tuber calcanei. The lateral plantar branch usually arose about $1 \mathrm{~cm}$. proximal to the origin of the medial one. The medial plantar artery ran at first along the medial border of the deep flexor tendon detaching its superficial branch which formed the planter common digital arteries II-IV. The artery then passed under the deep flexor tendon as the deep branch to anastomose with the lateral plantar artery, forming a short trunk which in turn anastomosed with the proximal perforating artery II to form the deep plantar arch (arcus plantaris profundus) (Fig 3/22).

\section{Aa. digitales plantares com- munes II, III, IV}

The $2^{\text {nd }}, 3^{\text {rd }}$ and $4^{\text {th }}$ common plantar digital arteries (Fig 3/23, 24, 25) represented the superficial set of the arteries supplying the planter aspect of the hind paw. It detached from the superficial branch of the medial planter artery about the middle of the metatarsal bones. Each plantar common digital artery communicated with the corresponding dorsal common digital artery through the interdigital arteries, near the fetlock joint. At the level of the metatarso-phalangeal joint, each plantar common digital artery bifur- cated into the lateral proper plantar digital artery of the same digit and the medial proper plantar digital artery of the succeeding one.

\section{Aa. digitales plantares proprea:}

The proper plantar digital arteries passed on the plantar aspect of the digits and detached the plantar branches of the proximal, middle and distal phalanges respectively.

The medial and lateral proper plantar digital arteries (Fig 4/26, 27 respectively) showed plantar anastomoses on the middle phalanx ( $R$. tori digitalis) to supply the digital torus and then ended within the distal phalanx as the terminal arch.

\section{Aa. metatarseae plantares}

The plantar metatarsal arteries II, III, IV (Fig 4/28, 29, 30 respectively) represented the deep set of the arteries supplying the planter aspect of the hind paw. It derived from the distal border of the deep planter arch as it crossed the superficial digital flexor tendons in the grooves between the metatarsal bones. Near the distal third of the metatarsal bone, each planter metatarsal artery anastomosed with the corresponding dorsal metatarsal artery by the distal perforating branch also was connected with the plantar common digital artery. The fourth deep plan- 
tar metatarsal arteries supplied the lateral side of the fifth digit (Fig 4/31).

\section{Ultra-sonography investigation}

\section{(Fig 5)}

The flowing of the blood is anechoic in all vessels. The diameter of the common dorsal digital artery was $(0.17 \mathrm{~cm})$, the diameter of the dorsal metatarsal artery was $(0.13 \mathrm{~cm})$ while the diameter of the common plantar digital artery was $(0.23 \mathrm{~cm})$ but the diameter of the plantar metatarsal artery was $(0.19 \mathrm{~cm})$ and the diameters of the medial and lateral proper digital arteries were 0.8 and $0.9 \mathrm{~cm}$ respectively.

\section{Discussion}

The present study revealed that, the arterial blood supply of the hind paw region in the cat was mainly achieved by the saphenous artery and the cranial tibial artery. This observation was assisted in other mammalian species by Lundborg \& Myrhage (1977) in human, Kang et al., (1990) in chicken, Jones et al., (2000) and Farg (2002) in rabbit.

The present study on the cat hind paw revealed that, the important main arteries of the hind paw were the superficial and deep dorsal and plantar arteries and their relation with the saphenous artery and dorsal pedal artery, that supported by
Funke and Kuhn (1998) in the same animal.

The current investigation recorded that the saphenous artery divided into two branches smaller cranial branch which gives off the superficial dorsal metatarsal arteries II, III, IV and large caudal branch that detaches the medial and lateral plantar arteries and continues as superficial plantar metatarsal arteries at the fetlock joint. This finding agrees with that of Sisson and Grossman (1969) and Evans (1993) in dog and cat.

The results applied in this study were in agreement with Budras et al., (2007) in the dog. They mentioned that the dorsal common digital arteries I- IV pass on the dorsum of the pes, from the cranial branch of the saphenous artery, while on the plantar surface, the plantar common digital arteries II-IV pass from the medial plantar artery, also, the plantar metatarsal arteries II-IV arise from the deep plantar arch which is supplied by the lateral plantar artery and the perforating metatarsal artery that derived from dorsal metatarsal II.

The current study approved that the dorsal common digital arteries II, III, IV are short vessels, which give off medial and lateral dorsal proper digital arteries, similar to that described by Evans (1993) in dog, Farag 
(2002) and Rezk and El bably (2012) in rabbit.

In this context, the present study reported that, the $5^{\text {th }}$ lateral dorsal digital artery originated from the common trunk of the $3^{\text {rd }}$ and $4^{\text {th }}$ dorsal common digital arteries that disagree with Sisson and Grossman (1969) in dog, who mentioned that, the cranial tibial artery supplied the fifth dorsal digital artery for lateral side of its digit.

In accordance with Dyce et al., (2010), the cranial tibial artery crosses the dorsal aspect of the hock, as the dorsal pedal artery, and gives rise to the dorsal metatarsal arteries among other branches. The second metatarsal arteries reinforces the caudal branch of the saphenous on the plantar aspect of the limb after passing between the second and third metatarsal bones as perforating metatarsal artery.

The same was described by Sisson and Grossman (1969) and Evans (1993) in dog as the cranial tibial artery continues opposite the tarsal joint as dorsal pedal artery which gives off medial and lateral tarsal arteries, arcuate artery which detached the superficial dorsal set of arteries and terminate as perforating metatarsal artery which pass to the plantar side between the second and third metatarsal bones. According to these findings and supported by the description of Evans (1993) in dog, the short trunk formed by anastomoses of the two plantar arteries with the perforating metatarsal artery to form the plantar arch. The latter, gives off the deep plantar metatarsal arteries II, III, IV.

Concerning to Evans (1993) in dog, the superficial and deep dorsal and plantar arteries of the hind paw are accompanied by communicating bran-ches as interdigital artery.

Accurate description of the arterial anatomy as well as ultrasonography or the arteriographic technique allowed interpretation of the changes occurring in the vasculature after injury in a fracture model (McNally et al., 1992). However, duplex ultrasonography is feasible and valid alternative to contrast arteriography in the diagnostic treatment of these patients (Harriet et al., 1992).

A more likely interpretation of our findings is supported by (O'Ceallaighet et al., 2006) who reported that the patent functional vessels and demonstrated vessels within the digit measured only several micrometers in diameter.

Our results are, therefore, compatible with the view mentioned by Car- 
tee, R. E. et al., (1995) in the horse, that the plantar branches of the cranial tibial artery may also be seen on the medial and lateral sides of the metatarsal region

These results concluded that the arterial pulse may be used to distinguish arteries and veins. In some cases, the proximity of the artery to the vein may cause the appearance of a pulse in the vein. Color and pulsed Doppler examination may quickly distinguish the two vessels (Cartee, R. E. et al., 1995). Veterinary anesthesia in pet animals was applied by inserting a catheter in the dorsal pedal artery or dorsal metatarsal arteries. This pattern was asserted by Dugdale, A. (2010), so using of ultrasonograph tools is effective in accurate measuring of the diameter of the artery however, it cannot totally represent or replace the traditional dissected specimens.

\section{Reference}

Barr, F. and Gaschen, L. (2011): BSAVA Manual of Canine and Feline Ultrasonography (BSAVA British Small Animal Veterinary Association).

Bednarski, R.M. (1996): Anesthesia and Immobilization of Specific Species (Dogs and Cats): In: Thurmon, J.C., Tranquilli, W.J., and Benson, G.J.: Lumbs and Jones' veterinary anesthesia. $3^{\text {rd }}$ ed., Williams and Wilkins, Baltimore, pp. 591-598.

Budras K. D., McCarthy P. H., Fricke W. Richter R. Horowitz A. and Berg R. (2007): Anatomy of the Dog: An Illustrated Text, Fifth Edition, Schlutersche Verlagsgesellschaft $\mathrm{GmbH}$ and Co.KG, HansBockler-Allee, Frankfurt- Germany.

Cartee R. E., Selcer B. A., Hudson J. A., Finn- Bodoner S. T., Mahaffey M. B., Johnson P. L. and Marich K. W. (1995): Practical Veterinary Ultrasound, "A Lea and Febiger book" library of congress cataloging, A Waverly company; Williams and Wilkins.

Caster J. D., Cummings C.A., Moneta G. L., Taylor Jr., Lloyd M., Porter J. M. (1992): Accuracy of Tibial Artery Duplex Mapping (TADM), Journal of Vascular Technology, 16,(3): 63-68(6).

Dugdale A. (2010): Veterinary Anaesthesia: Principles to Practice, John Wiley and Sons, Southern Gate, Chichester, United Kingdom.

Dyce K.M., Sack W.O. and Wensing C. J. G.(2010): Text book of Veterinary Anatomy, Fourth Edition, Saunders, Elsevier, China. 
Evans H. E. (1993): Miller's Anatomy of the dog, 3rd edition. W.B. Saunders Company. Philadelphia, Pennsylvania.

Farag F. M. (2002): The arterial supply of the hind paw in the rabbit. Beni-suef vet. j. med.12 (1): 113129.

Funke C.and Kuhn H. J. (1998): The morphogenesis of the arteries of the pelvic extremity. A comparative study of mammals with special reference to the tree shrew Tupaia belangeri (Tupaiidae, Scandentia, Mammalia). Adv AnatEmbryol Cell Biol., 144:1-97.

Harriet H., Alberto C., Harry R. , Paolo P., Jan W. (1992): Detection of Deep Vein Thrombosis With Impedance Plethysmography and Real-Time Compression Ultrasonography in Hospitalized Patients, Arch Intern Med., 152(9):1901-1903.

Jones M. E., Ladhani K., Mudera V., Grobbelaar A. O., McGrouther D. A., Sanders R. (2000): Flexor tendon blood vessels, J. Hand Surg Br.; 25(6):552-9.

Kang H. J., Park B. M., Hahn S. B., Kang E. S. (1990): An experimental study of healing of the partially severed flexor tendon in chick- ens. Yonsei Med J.1990; 31:264273. [PubMed]

Lundborg G., Myrhage R. (1977): The vascularization and structure of the human digital tendon sheath as related to flexor tendon function. An angiographic and histological study.Scand J PlastReconstr Surg. 1977;11:195-203. [PubMed]

Meredith A. (2009): Rabbits, Royal (Dick) School of Veterinary Studies, University of Edinburgh http://www.aquavet.i12.com/Rabbit. html (accessed 02.04.09).

McNally M. A., Small J. O., Mollan R. A. B. And Wilson D. J. (1992): Arteriographic study of the rabbit lower limb, The Anatomical Record, 233 (4): 643-650

\section{Nomina Anatomica Veterinaria} 5th ed. (2005): published by Committee on Vet. Anat. Nomenclature of the world association of Vet. Anatomists, Hannover.

O'Ceallaigh S., Herrick S. E., Bluff J. E., McGrouther D. A., Ferguson M. W.(2006): Quantification of total and perfused blood vessels in murine skin autografts using a fluorescent double-labeling technique. Plast Reconstr. Surg. 2006; 117: 140- 151. [PubMed] 
Rezk, H. M. and El-Bably, S. H. $(r+1 r)$ : Gross anatomical studies on the arterial supply of the manus region in the rabbit.SCVMJ, XVII (2): 299-308.
Sisson, S. and Grossman, J. D. (1969): The anatomy of the domestic animals. 4th ed. W. B. Saunders, Philadelphia, London.

\section{Correspondence address:}

Hamdy Rezk

Department of Anatomy, Faculty of veterinary medicine, Cairo University

Email: hamdyrezk81@cu.edu.eg

: doc hamdy6381@yahoo.com 

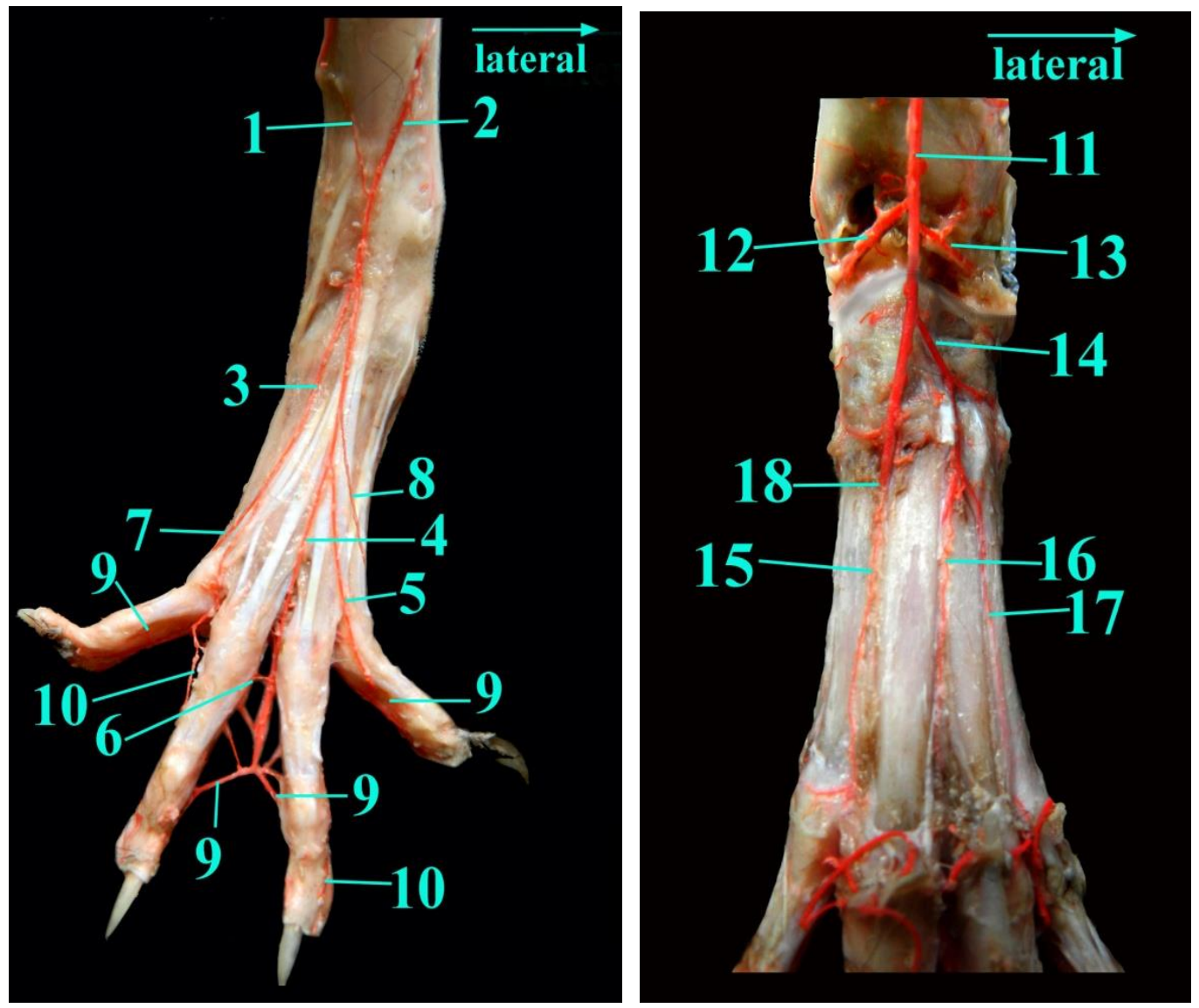

Fig (1): (Left) A photograph showing the arterial supply of the dorsal aspect of the left hind paw in cat (Superficial layer).

Fig (2): (Right) A photograph showing the arterial supply of the dorsal aspect of the left hind paw in cat (Deep layer).

$1 \mathrm{~A}$. saphenous ( ramus cranialis), $2 \mathrm{~A}$. tibialis cranialis, $3 \mathrm{~A}$. digitalis dorsalis communis II, $4 \mathrm{~A}$. digitalis dorsalis communis III, $5 \mathrm{~A}$. digitalis dorsalis communis IV, 6 A. interdigitalis, $7 \mathrm{~A}$. digitalis dorsalis II abaxialis , 8 A. digitalis dorsalis $\mathrm{V}$ abaxialis, 9 Aa. digitales dorsales II, III, IV, V axiales, 10 Aa. digitales dorsales III, IV abaxiales, $11 \mathrm{~A}$. dorsalis pedis, $12 \mathrm{~A}$. tarsea medialis, 13 A. tarsea lateralis, $14 \mathrm{~A}$. arcuata, $15 \mathrm{~A}$. metatarsea dorsalis profundus II, $16 \mathrm{~A}$. metatarsea dorsalis profundus III, 17 A. metatarsea dorsalis profundus IV. 

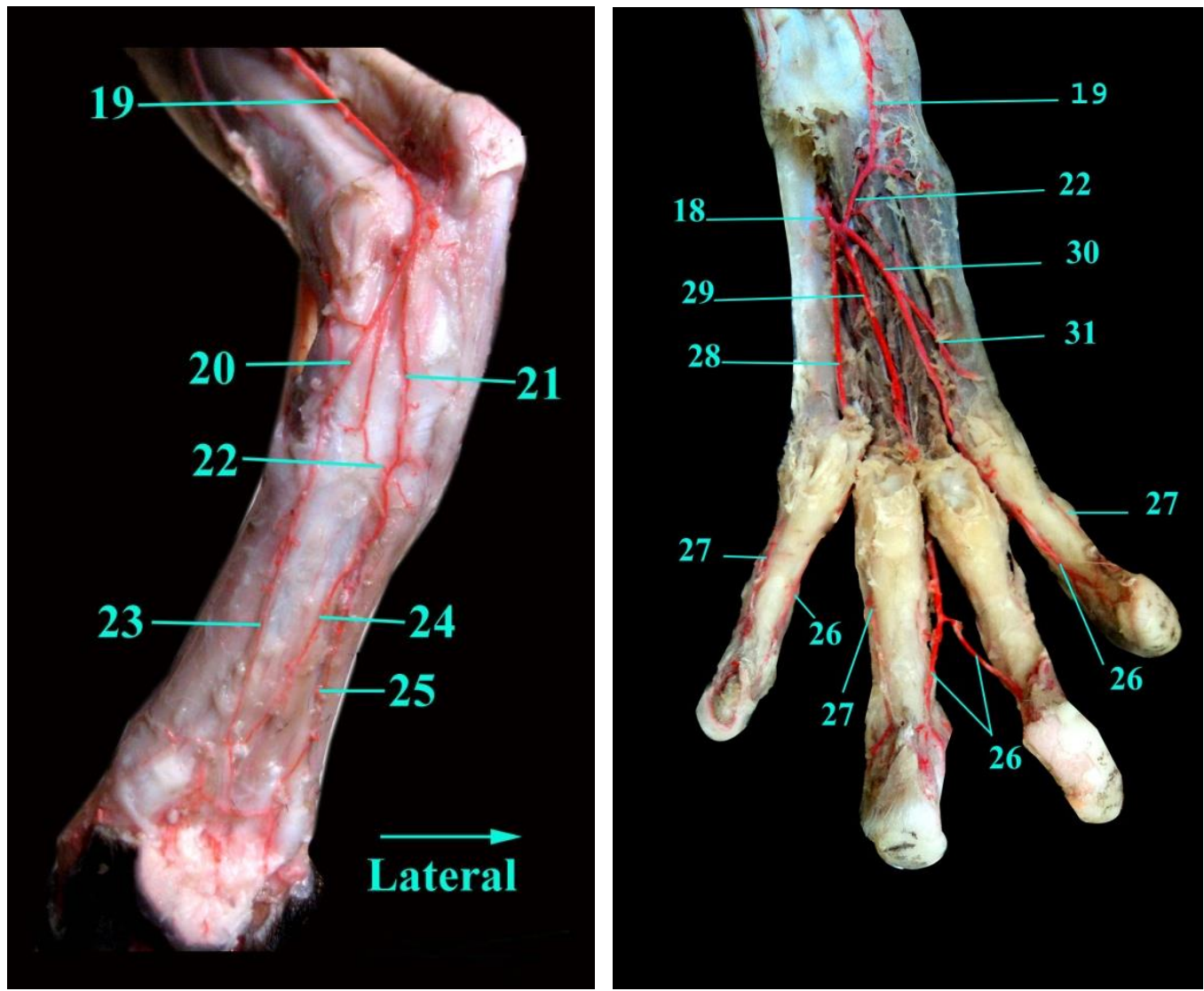

Fig (3): (Left) A photograph showing the arterial supply of the plantar aspect of the right hind paw in cat (superficial layer).

Fig (4): (Right) A photograph showing the arterial supply of the plantar aspect of the left hind paw in cat (Deep layer).

18 Ramus perforans proximalis II, 19 A. saphenous (ramus caudalis), 20 A. plantaris medialis, $21 \mathrm{~A}$. plantaris lateralis, 22 Arcus plantaris profundus, $23 \mathrm{~A}$. digitalis plantaris communis II, $24 \mathrm{~A}$. digitalis plantaris communis III, 25 A.digitalis plantaris communis IV, 26 A. digitales plantaris axialis, 27 A. digitalis plantaris abaxialis, $28 \mathrm{~A}$. metatarsea plantaris profundus II, $29 \mathrm{~A}$. metatarsea plantaris profundus III, $30 \mathrm{~A}$. metatarsea plantaris profundus IV, $31 \mathrm{~A}$. metatarsea plantaris profundus $\mathrm{V}$. 

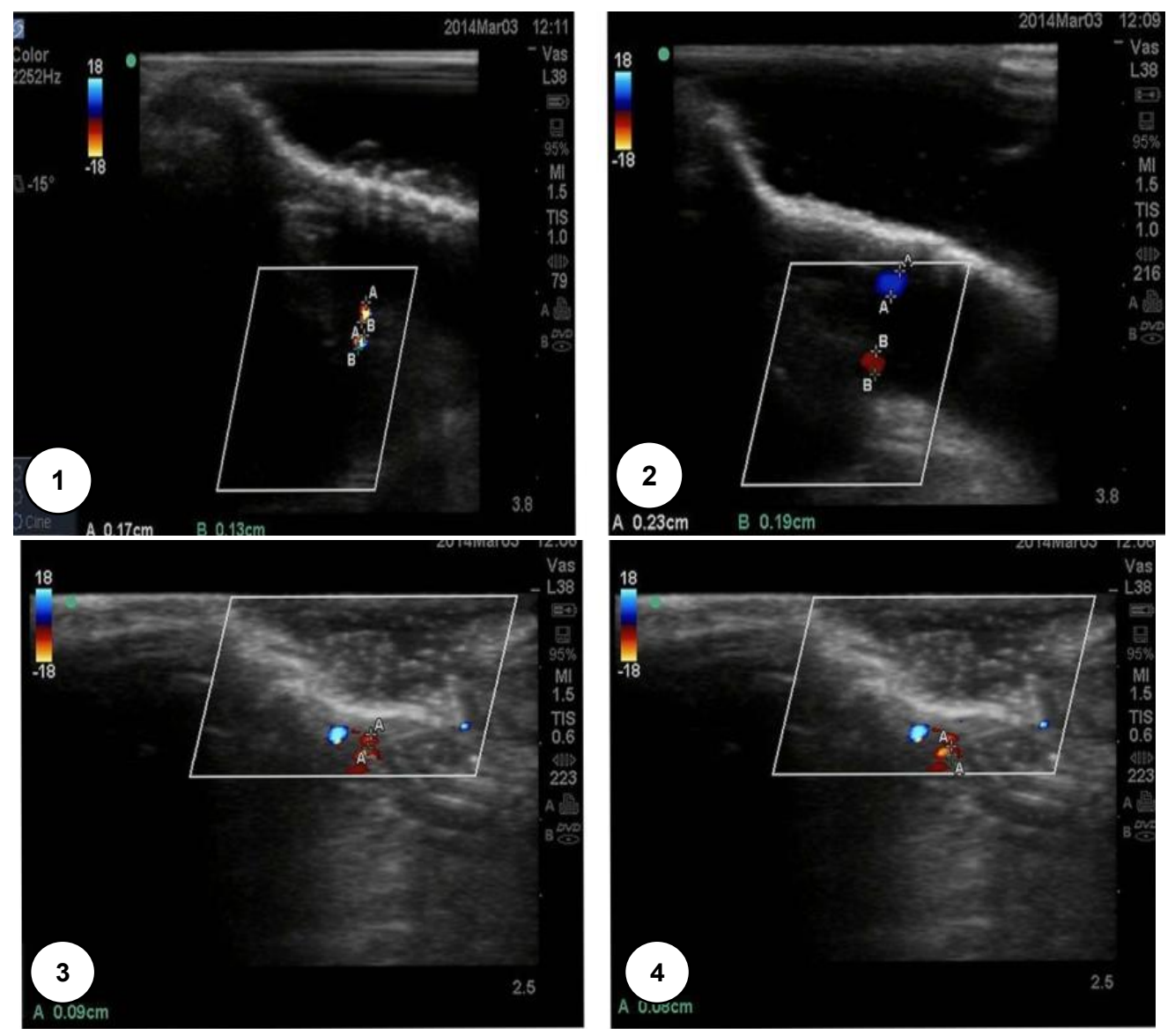

Fig (5): ultrasonographic images showing the diameter of each artery of the hind paw in cat.

1. A, Aa.digitales dorsales communes

$\mathrm{B}, \mathrm{Aa}$. metatarseae dorsales

2. A, Aa. digitales plantares communes

$\mathrm{B}, \mathrm{Aa}$. metatarseae plantares

3. Aa. digitales plantares axiales

4. Aa. Digitales plantares abaxiales 